International Journal of Biomedicine | June 2021 - Volume 11, Issue Suppl_1: Abstracts from the Third Russian International Conference "Cryo-electron microscopy 2021: achievements and prospects"

\author{
POSTER ABSTRACT PRESENTATIONS
}

SESSION TITLE: EM RESEARCH RELATED TO MEDICINE

DOI: 10.21103/JJBM.11.Suppl_1.P39

\title{
Abstract P-39: Fluorescent Silver Nanoclusters with Immunoglobulins and Albumins
}

Olga V. Morozova, Nataliya V. Shevlyagina, Vladimir G. Zhukhovitsky

National Research Center of Epidemiology and Microbiology of N.F. Gamaleya of the Russian Ministry of Health, Moscow, Russia

Background: Multiplex biomedical assays including molecular genetic tests and immunoanalysis require multiple fluorophores with a wide excitation range and different emission spectra. In comparison with organic fluorophores and quantum dots, the metal nanoclusters (NC) consisting of a few to hundred atoms have the following advantages: small size, large Stokes shift, prolonged fluorescence lifetime and biocompatibility. Our research was aimed at construction of fluorescent AgNC with the main blood proteins and transmission electron microscopy (TEM).

Methods: $\mathrm{AgNC}$ were synthesized from $\mathrm{AgNO}_{3}$ in the presence of albumins and immunoglobulins (Ig) of different classes and origin at $\mathrm{pH}$ 9-11 with $\mathrm{NaBH}_{4}$ recovery. The resulting AgNC with proteins were loaded to "Formvar/Carbon 200 Mesh Copper" copper grids (Ted Pella, USA) and examined using TEM system JEM 2100 Plus (JEOL, Japan) without contrast. Fluorescence excitation/emission spectra were measured in quartz cuvette using the FluoroMax + spectrofluorometer (Horiba Scientific, Japan).

Results: Recovery of $\mathrm{Ag}+$ ions did not occur in the presence of $\operatorname{IgG}$ and albumins without $\mathrm{NaBH}_{4}$ at different temperatures, $\mathrm{pH}$, and incubation time. Broad excitation spectra of AgNC were in a range 340-540 nm. Their emission spectra correlated with the original $\mathrm{AgNO}_{3}$ concentration and did not depend on protein and $\mathrm{pH}$. $\mathrm{NC}$ stabilized with $\mathrm{IgG}$ or albumin with blue fluorescence and emission maximum at $420 \mathrm{~nm}$ contained NC from $0.6 \mathrm{~nm}$ and higher. Green AgNC with proteins had bright fluorescence at $430-470 \mathrm{~nm}$ and red NC showed emission maximum at 650 $\mathrm{nm}$. TEM revealed discrete AgNC and their numerous aggregates in each sample of fluorescent $\mathrm{NC}$ in spite of different fluorescent emission spectra. 
According to the MTT test, AgNC with human $\operatorname{IgG}$ and BSA with protein concentrations up to $3 \mathrm{mg} / \mathrm{ml}$ were not toxic for human larynx carcinoma HEp-2 cells despite cytotoxicity of silver nanoparticles covered with IgG or albumin envelopes as well as $\mathrm{Cd}$ and AuNC with BSA.

Conclusion: AgNC with antibodies and albumin with a broad size range and aggregation possess tunable fluorescence emission spectra with broad excitation at 340-540 nm. Different emission spectra permit AgNC to be used in multiplex assays. AgNC were not toxic for human tissue culture and may be applied for bioimaging.

Key Words: silver nanoclusters $\bullet$ fluorescent spectra $\bullet$ TEM $\bullet$ cytotoxicity

*Corresponding author: Olga V. Morozova. E-mail: omorozova2010@gmail.com

International Journal of Biomedicine. 2021;11 Suppl 1: S29.

doi: 10.21103/IJBM.11.Suppl_1.P39

(C)2021 International Medical Research and Development Corporation 